\title{
RESEARCH ON THE INFLUENCING FACTORS OF EXCESSIVE CONSUMPTION ONLINE -- BASED ON THE THEORY OF PLANNED BEHAVIOR
}

\author{
Yanping Tao \\ Business School, Sichuan University, P.R. China \\ Junyi Meng \\ Business School, Sichuan University, P.R. China \\ Lu Huang* \\ Business School, Sichuan University, P.R. China
}

\begin{abstract}
With the development of Internet economy, the excessive consumption in online shopping has gradually become a social problem. The existing research on excessive consumption is mainly from the irrational consumption, in fact, the excessive consumption in the specific form of expression, the influencing factors have their own unique characteristics. Based on the TPB, the theory of planned behavior can be used to explain the excessive consumption in online shopping. Among them, behavior attitude has a greater impact on the excessive consumption intention, while subjective norm has little influence on it. Besides, perceived behavioral control has an impact on the intention and behavior of the excessive consumption. Therefore, it is important to discuss how to reduce excessive consumption and guide consumers to establish a correct view of consumption.
\end{abstract}

Keywords: excessive consumption online; theory of planned behavior; excessive consumption intention

JEL code: D12

\section{Introduction}

In the echo of Electronic Commerce, online shopping has become a necessity in people's lives. According to 2016 Chinese Online Shopping Insight Report and Online Shopping Guide by China Electronic Commerce Research Center, despite that the increment of online retail market transaction began to level off, the overall scale of that, which has reached 5 trillion in 2016, is still expanding.

Under such circumstances as increasing number of on-line shoppers, enlarging trades scale, and heavily sales promotion during "Double 11" and "Double 12", which are Chinese Internet Shopping Days, excessive consumption, a prevalent phenomenon that purchases exceeding demands and consumption exceeding economic capacity as well as addiction to purchasing online, has become a social problem. Far from saving our time and money as it seems, convenient purchasing on the Internet, on the other hand, also cause unnecessary waste in the whole society. Consequently, it is of great vitality to research into the origin of excessive

\footnotetext{
*Corresponding Author. Email: hl.scu@163.com

Foundation: the Fundamental Research Funds for the Central Universities (No.skqy201648).
} 
consumption, and advocate moderate expenditure ethics among both individuals and the whole society.

Recent study on online consumption at home and abroad mainly focuses on irrational consumption and impulsive purchase. With regard to excessive consumption, research is comparatively insufficient without clear definition and systematized study on its influencing factors. Therefore, based on the previous study, the research will concentrate on the over consumption on the Internet and its manifestations, and, moreover, an empirical research grounded on the Theory of Planned Behavior will be conducted into its influencing factors.

\section{Literature Review}

Present literature shows that most study on excessive consumption have largely focused on irrational consumption. Scholars from home and abroad have carried extensive discussion on it from many perspectives, but the boundaries between over and irrational consumption still remains vague. It is generally accepted that excessive consumption is a behavior to consume beyond one's demand and economic ability which might cause social disorder and a waste of resources. By comparing connotations of the two terms, we can conclude differences in definition, classification and factors (Table 1). Irrational consumption is a decision-making behavior when individuals violate utility maximizing rule. It is universal because there is only limited rationality in customers. Therefore, they are likely to be induced to make unreasonable decision by external factors like promotion and purchase situation. Excessive Consumption, on the other hand, underlines an extension of objective boundaries like individual's external demand and economic capacity. It is still irrational consumption in essence, but have distinctive formative characteristics and influencing factors. 
Table1.Comparison between Irrational Consumption and Excessive Consumption

\begin{tabular}{|c|c|}
\hline \multirow{4}{*}{ Definition } & Irrational Consumption \\
\hline & $\begin{array}{l}\text { Irrational consumption is a behavior that consumers violate utility maximization under } \\
\text { different preference. (Kahneman,1979) } \\
\text { Irrational consumption is the violation of utility (satisfaction) maximization rule where } \\
\text { consumers select the acceptable alternatives rather than a certain maximum. (Simon,1956) } \\
\text { Irrational consumption is illogical consumption. (Malthus) } \\
\text { Irrational consumption is a non-standard consuming behavior which exceeds given } \\
\text { constraints. (Huang Dehai,2000) } \\
\text { Irrational consumption behavior refers to the unreasonable consumer's decision due to } \\
\text { various unreasonable factors. (Huang Shoukun,2005) }\end{array}$ \\
\hline & Excessive Consumption \\
\hline & $\begin{array}{l}\text { Excessive consumption refers to consumption levels that exceed the objective limits and are } \\
\text { incompatible with the level of development of productive forces. (Lin Baipeng,1991) } \\
\text { Excessive consumption refers to the consumption patterns beyond real economic conditions } \\
\text { and reasonable demand. (Wang Fengnian,2002) } \\
\text { Excessive consumption generally refers to the consumption that exceeds consumer's ability } \\
\text { or demand. Irrational,unhealthy consumption is also included..(Li Qingyi,2005) }\end{array}$ \\
\hline \multirow{4}{*}{ Classification } & Irrational Consumption \\
\hline & $\begin{array}{l}\text { Impulsive and inert. (Becker) } \\
\text { Consumption due to loyalty, temptation and conformity. (Huang Heshui,2005) } \\
\text { Consumption that 1) fail to maximize utility, 2) fail to meet the law of diminishing marginal } \\
\text { utility, 3) fail to take into account the constraints like income or income classes, 4) caused } \\
\text { by wrong expectations involving risks and opportunities, and 5) abnormal consumption. } \\
\text { (Huang Shoukun,2005) } \\
\text { Impulsive buying, conformity buying, compulsive buying and conspicuous buying. }\end{array}$ \\
\hline & Excessive Consumption \\
\hline & $\begin{array}{l}\text { premature consumption, conspicuous consumption and morbid consumption. (Li } \\
\text { Qingyi,2005) } \\
\text { premature consumption, squandering consumption. (Liang Jia, Wang Yan, 2007) } \\
\text { Debt consumption, conspicuous consumption and morbid consumption. (Zhu Ling,2006) }\end{array}$ \\
\hline \multirow{4}{*}{$\begin{array}{l}\text { Influencing } \\
\text { Factors }\end{array}$} & Irrational Consumption \\
\hline & $\begin{array}{l}\text { Convenience of payment. (Dutta,2003) } \\
\text { Sales, promotions and suggestions. (Sandy Dawson \& Minjeong Kim,2010) } \\
\text { Interactivity and vividness of Website. (Kathy Ning Shen,2012) } \\
\text { Stimulus provided by manufactures, situation when purchasing and individual } \\
\text { characteristics. (Chen Minghui,2001) } \\
\text { Knowledgeability, entertainment, interactivity and security of a website. (Wang } \\
\text { Qingsen,2008) } \\
\text { Consumer psychology, the buying situation and features of product. (Zhu Xiaodan,2011) }\end{array}$ \\
\hline & Excessive Consumption \\
\hline & $\begin{array}{l}\text { From the sociological and psychological point of view, the inherent fundamental driving } \\
\text { factor of excessive consumption is people's psychology of conformity and conspicuousness. } \\
\text { (Li Wei,2006) } \\
\text { Vanity, "mianzi"consumption in the traditional culture, the concept of carpe diem among } \\
\text { young people, atmosphere of high consumption by business advocacy , the impact of new } \\
\text { consumption method and the impact of Western consumption patterns.(Zhai Honghua,2011) }\end{array}$ \\
\hline
\end{tabular}

On the other hand, Excessive Consumption in Network Economy differs from traditional one in the past as well. Compared with traditional excessive consumption which is generally out of ostentation or conformity for consumers in order to gain identity or admiration from others, excessive consumption in the era of Internet emerges with considerably complex reasons.For example, over and useless consuming due to sales promotion or a low price, premature consumption brought by the development of credit consumption, as well as morbid consumption for addiction to shopping on-line. Therefore, based on traditional one, Internet excessive consumption here is defined as a behavior of online consumption that exceeds customers' real demand and economic capability due to a lack of rationality under network 
marketing, and will therefore lead to a waste of resources.

\section{Empirical research of EC based on TPB}

\subsection{The Theory of Planned Behavior in online consuming}

The Theory of Planed Behavior (TPB) is proposed in 1985 by Ajzen grounded on its predecessor, Theory of Reasoned Action (TRA). It assumes that customer's behavior is influenced by behavioral intention, which is further determined by individual's attitude and subjective norm. Given by Ajzen that most individuals behave under a existence of both rationality and its opposite, he introduced TPB by including another construct: Perceived Behavioral Control (PBC).

TPB is widely applied in the realm of consumer behavior because of its effectiveness in explaining and predicting consumers' intention and behavior. The importance of PBC in this model is later verified by the greatly improved power to interpret after the inclusion of this variable (Sheeran 2003). Madden et al. (1992) confirmed that TPB, compared with TRA, performs better in explaining consumer behavioral intention and behavior. Current research indicates that the theory can also be applied in the study of online purchasing. Hansen believed that it can be employed on the study of online purchasing intention. Research by Gopi et al. also reports a positive correlation between intention when shopping online and influencing factors as behavioral attitude, subjective norm and perceptual behavioral control. Orbell's study (2001) demonstrated that three factors above can account for $77 \%$ of total variation. Research also discloses that TPB can predict effectively on continuous online shopping intention.

\subsection{Hypothesis and Research Model}

Based on TPB, the research will construct the model of how the factors affect excessive consumption (EC) online. The research assumes that (1) individual's behavioral attitude (BA), subjective norms(SN) and perceived behavioral control(PBC) related to excessive consumption not only affect each other but also amalgamate to influence the intention of excessive consumption, (2) which further determines the behavior of over consumption. Among all the factors, attitude toward excessively consume denotes a customer's positive or negative evaluation of performing the behavior; SN on EC refers to consumer's perception of the social pressure from important others about whether to consume excessively; PBC over EC is defined as a customer's perception of how easy or difficult it would be to carry out excessive consumption and the controllability over excessive consumption. EC intention is the tendency for a customer to consume excessively; and finally EC behavior is the specific excessively consuming activity when purchasing product online.

Following TPB, the research reckons that there is interplay among consumer's attitude, subjective norm and perceived behavioral control, and the three factors directly influence the behavioral intention of excessive consumption. Therefore, we suggest that:

H1: Attitude to consume excessively and SN on consuming excessively positively influence each other.

H2: $\quad$ SN on consuming excessively and PBC over consuming excessively positively influence each other.

H3: Attitude to consume excessively and PBC over consuming excessively positively influence each other. 
H4: Attitude to consume excessively positively influences customer's intention to consume excessively.

H5: SN on consuming excessively positively influences customer's intention to consume excessively.

H6: $\quad$ PBC over consuming excessively positively influences customer's intention to consume excessively.

H7: Intention to consume excessively positively influences customer's behavior to consume excessively.

At the same time, Ajzen referred that PBC can also be employed in purchase prediction. It is indicated by Kraft (2005) that PBC is the belief for people to accomplish a certain goal which , by present research, will distinctly affect individual's behavior. Therefore, the research assumes that:

H8: $\quad$ PBC over consuming excessively positively influences customer's behavior to consume excessively.

In conclusion, we propose the modeling as follows:

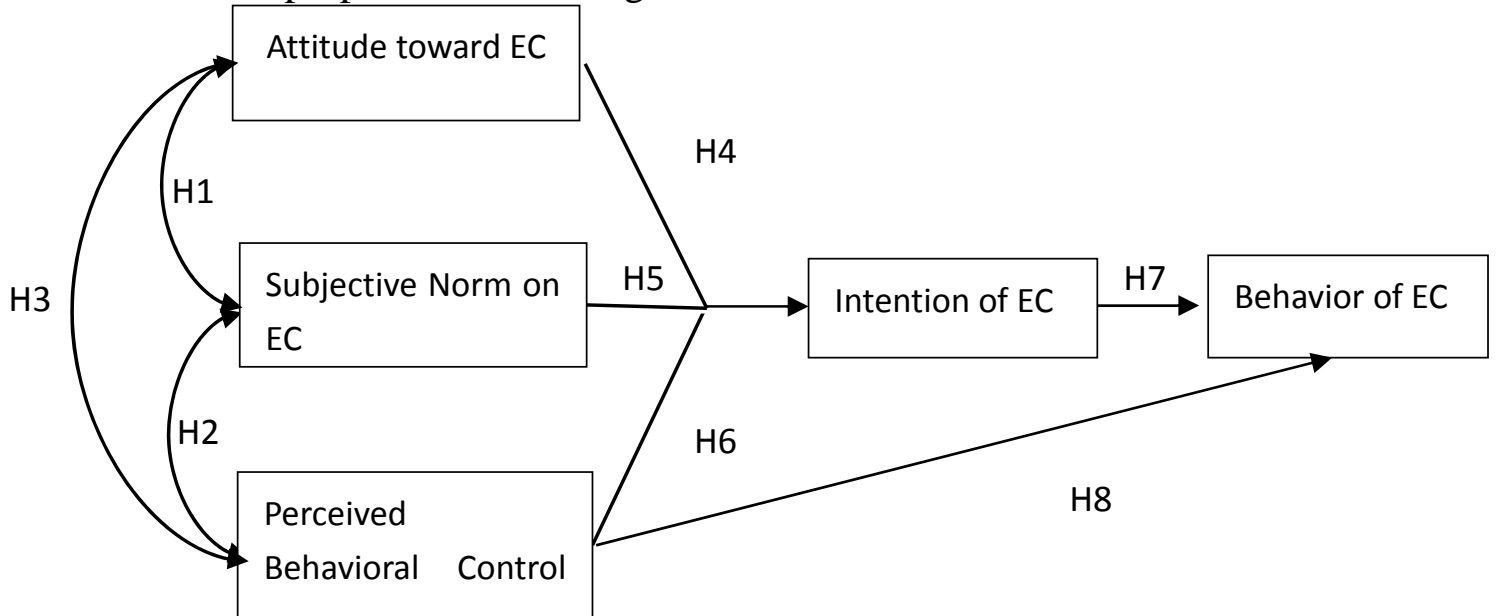

Figure 1. The Excessive Consumption Extension of the Theory of Planned Behavior

\section{Research Methodology}

\subsection{Measurement Development}

This research mainly focuses on the behavior of participants related to excessive consumption online, including online purchase on credit or installment plan, quantity buying that exceeds demand when encountering promotion, buying unnecessary commodity and uncontrolled impulsive purchasing whenever it is possible.

The key variables include attitude toward excessive consumption, subjective norm on excessive consumption, perceived behavioral control over excessive consumption and intention to purchase excessively. All measurement items were drawn form maturity scale abroad and then adapted according to our specific scenario into lists below: 
Table2 Measurement of variables

\begin{tabular}{|c|c|c|}
\hline Construct & Measurement Items & Resource \\
\hline \multirow{3}{*}{$\begin{array}{l}\text { Intention of } \\
\text { EC }\end{array}$} & A1.I intend to consume excessively recently. & \multirow{3}{*}{$\begin{array}{l}\text { O'Cass\&Fenech(2003); } \\
\text { Hoffman\&Novak(1999) }\end{array}$} \\
\hline & $\begin{array}{l}\text { A2.I would consider about consume excessively to some } \\
\text { extent. }\end{array}$ & \\
\hline & A3.I would consume excessively if it is possible. & \\
\hline \multirow{3}{*}{$\begin{array}{l}\text { Attitude } \\
\text { toward EC }\end{array}$} & $\begin{array}{l}\text { B1. For me, excessive consumption would be a very } \\
\text { good idea. }\end{array}$ & \multirow{3}{*}{ George J F(2004) } \\
\hline & B2.For me, excessive consumption would be very wise. & \\
\hline & B3.For me, excessive consumption would be beneficial. & \\
\hline \multirow{3}{*}{$\begin{array}{l}\text { Subjective } \\
\text { Norm on EC }\end{array}$} & $\begin{array}{l}\text { C1.Most people who are important to me think it is wise } \\
\text { to consume excessively. }\end{array}$ & \multirow{3}{*}{ Taylor\&Todd(1995) } \\
\hline & $\begin{array}{l}\text { C2.Most people who are important to me think it is } \\
\text { helpful to consume excessively. }\end{array}$ & \\
\hline & $\begin{array}{l}\text { C3.Most people who are important to me think it is } \\
\text { helpful to consume excessively. }\end{array}$ & \\
\hline \multirow{3}{*}{$\begin{array}{l}\text { Perceived } \\
\text { Behavioral } \\
\text { Control over } \\
\text { EC }\end{array}$} & $\begin{array}{l}\text { D1.Consuming excessively will be completely under my } \\
\text { control. }\end{array}$ & \multirow{3}{*}{ Taylor\&Todd(1995) } \\
\hline & $\begin{array}{l}\text { D2.If I wanted to, I could become knowledgeable about } \\
\text { excessively consumption. }\end{array}$ & \\
\hline & $\begin{array}{l}\text { D3.If I wanted to, I could become skillful at excessively } \\
\text { consumption. }\end{array}$ & \\
\hline
\end{tabular}

\subsection{Survey Administration}

The questionnaire is divided into three parts: the first part comprises instructions to complete the scales; second part is the body which distinctively tests respondents' attitude, subjective norm, perceived behavioral control, behavioral intention and behavior related to excessive consumption. All measurement items are tested in Likert Seven Scaling Method which is universally used, requiring respondents to rating among the choice from "extremely disagree" to "extremely agree"; and the third part is designed to access participants' demographic characteristics. Several pretests were conducted to confirm the measurement properties of the items and certify the validity and effectiveness of the study. Given that university students are the backbone of online purchasers with abundant online shopping experience, the pilot test were conducted with 50 Sichuan University students.All of the questionnaires are retrieved with validity.Then the items are refined according to pretest responses to make sure each particular is understandable, answerable and without various interpretation. Finally, the formal survey is shaped.

\subsection{Data Collection and Descriptive Statistics}

Formal test is conducted online through toll service provided by SoJump, an online survey platform in China. The final result comprised 321 effective samples, at an effectiveness rate of 91.71\%. 29 invalid samples completed within three minutes are eliminated considering the time-consuming process to fill massive items. The result is considerable representative with participants’ geographic position covering almost all part of the nation. 
Table3 Descriptive Statistics

\begin{tabular}{|c|c|c|c|}
\hline Items & Variables & Frequency & Ratio \\
\hline \multirow{2}{*}{ Gender } & Male & 158 & $49.37 \%$ \\
\hline & Female & 163 & $50.63 \%$ \\
\hline \multirow{4}{*}{ Age(Years) } & $18-25$ & 39 & $12.13 \%$ \\
\hline & $26-35$ & 207 & $64.44 \%$ \\
\hline & $36-45$ & 67 & $20.92 \%$ \\
\hline & 45 and above & 8 & $2.51 \%$ \\
\hline \multirow{4}{*}{ Education } & Middle School & 16 & $5.02 \%$ \\
\hline & $\begin{array}{c}\text { Post-secondary } \\
\text { Specialized School }\end{array}$ & 44 & $13.81 \%$ \\
\hline & Undergraduate & 235 & $73.22 \%$ \\
\hline & Postgraduate & 26 & $7.95 \%$ \\
\hline \multirow{4}{*}{$\begin{array}{c}\text { Internet } \\
\text { Experience } \\
\text { (Years) }\end{array}$} & Below 2 & 1 & $0.41 \%$ \\
\hline & $2-5$ & 42 & $12.97 \%$ \\
\hline & $6-8$ & 128 & $39.75 \%$ \\
\hline & 8 and above & 150 & $46.86 \%$ \\
\hline \multirow{4}{*}{$\begin{array}{c}\text { Average Sum } \\
\text { purchasing } \\
\text { online }\end{array}$} & Below 100 & 21 & $6.69 \%$ \\
\hline & $100-300$ & 191 & $59.41 \%$ \\
\hline & $300-500$ & 69 & $21.34 \%$ \\
\hline & 500 and above & 40 & $12.55 \%$ \\
\hline \multirow{4}{*}{$\begin{array}{c}\text { Frequency of } \\
\text { purchasing } \\
\text { online in the } \\
\text { past three } \\
\text { months }\end{array}$} & $0-3$ & 36 & $11.30 \%$ \\
\hline & $4-6$ & 95 & $29.71 \%$ \\
\hline & $6-8$ & 70 & $21.76 \%$ \\
\hline & 8 and above & 120 & $37.24 \%$ \\
\hline
\end{tabular}

\section{Data analysis}

\subsection{Measurement Validation}

Measure reliability of data collected was assessed using SPSS20.0. That Cronbach's Alpha of each scale exceeds 0.7 indicates that the scales are acceptable with tolerable reliability. On the other hand, derived and revised accordingly from maturity scales of present research, scales in the research demonstrate adequate validity. Furthermore, we conducted confirmatory factor analysis using AMOS21.0, testing the standard factor loadings and average variance extracted (AVE) of each latent variables. Both are reported higher than 0.5, signifying a well-performing internal quality and acceptable convergent validity. 
Table4 Reliability and validity for latent variables

\begin{tabular}{|c|c|c|c|c|}
\hline \multirow{2}{*}{ Variables } & Items & $\begin{array}{c}\text { Standard factor } \\
\text { loading }\end{array}$ & \multirow{2}{*}{$\begin{array}{c}\text { Cronbach's } \\
\text { Alpha }\end{array}$} & \multirow{2}{*}{ AVE } \\
\hline \multirow{2}{*}{$\begin{array}{c}\text { Behavioral } \\
\text { Intention }\end{array}$} & $\mathrm{A} 1$ & 0.894 & 0.803 & \multirow{2}{*}{0.622} \\
\cline { 2 - 3 } & $\mathrm{A} 2$ & 0.511 & \\
\hline \multirow{2}{*}{$\begin{array}{c}\text { Behavioral } \\
\text { Attitude }\end{array}$} & $\mathrm{A} 3$ & 0.898 & \multirow{2}{*}{0.940} & \multirow{2}{*}{0.841} \\
\cline { 2 - 3 } & $\mathrm{B} 1$ & 0.923 & \\
\hline \multirow{2}{*}{$\begin{array}{c}\text { Subjective } \\
\text { Norm }\end{array}$} & $\mathrm{B} 2$ & 0.925 & \multirow{2}{*}{0.949} & \\
\cline { 2 - 3 } & $\mathrm{B} 3$ & 0.903 & \\
\hline \multirow{2}{*}{$\begin{array}{c}\text { Perceived } \\
\text { Behavioral } \\
\text { Control }\end{array}$} & $\mathrm{C} 1$ & 0.929 & \multirow{2}{*}{0.863} \\
\cline { 2 - 3 } & $\mathrm{C} 2$ & 0.941 & 0.917 & \\
\cline { 2 - 3 } & $\mathrm{D} 3$ & 0.829 & 0.898 & \\
\hline
\end{tabular}

\subsection{Structural Equation Modeling}

Using AMOS21.0, we fit the proposed research model to processed data on the basis of structural equation modeling.

Goodness-of-fit index is listed as follows:

Table5 Goodness-of-fit Index of Default Model

\begin{tabular}{|l|l|l|l|l|l|l|}
\hline $\begin{array}{l}\text { Goodness-of-fit } \\
\text { index }\end{array}$ & $\mathrm{x}^{2} / \mathrm{df}$ & RMSEA & GFI & NFI & CFI & IFI \\
\hline Values & 1.735 & 0.040 & 0.994 & 0.996 & 0.997 & 0.997 \\
\hline
\end{tabular}

In the default model, the value of $\mathrm{x}^{2} / \mathrm{df}$ is 1.735 , indicating a good fit. According to Rong Taisheng (2009), in addition to chi-square statistic,examination of goodness-of-fit in structural equation modeling should include other criteria. Among all the index in the default model, RMSEA is less than 0.05, GFI, NFI, CFI, IFI are larger than 0.90, all falling into range of a good fit. Hence, the data fit well in the default model.

And we have the result of fit as follows: 


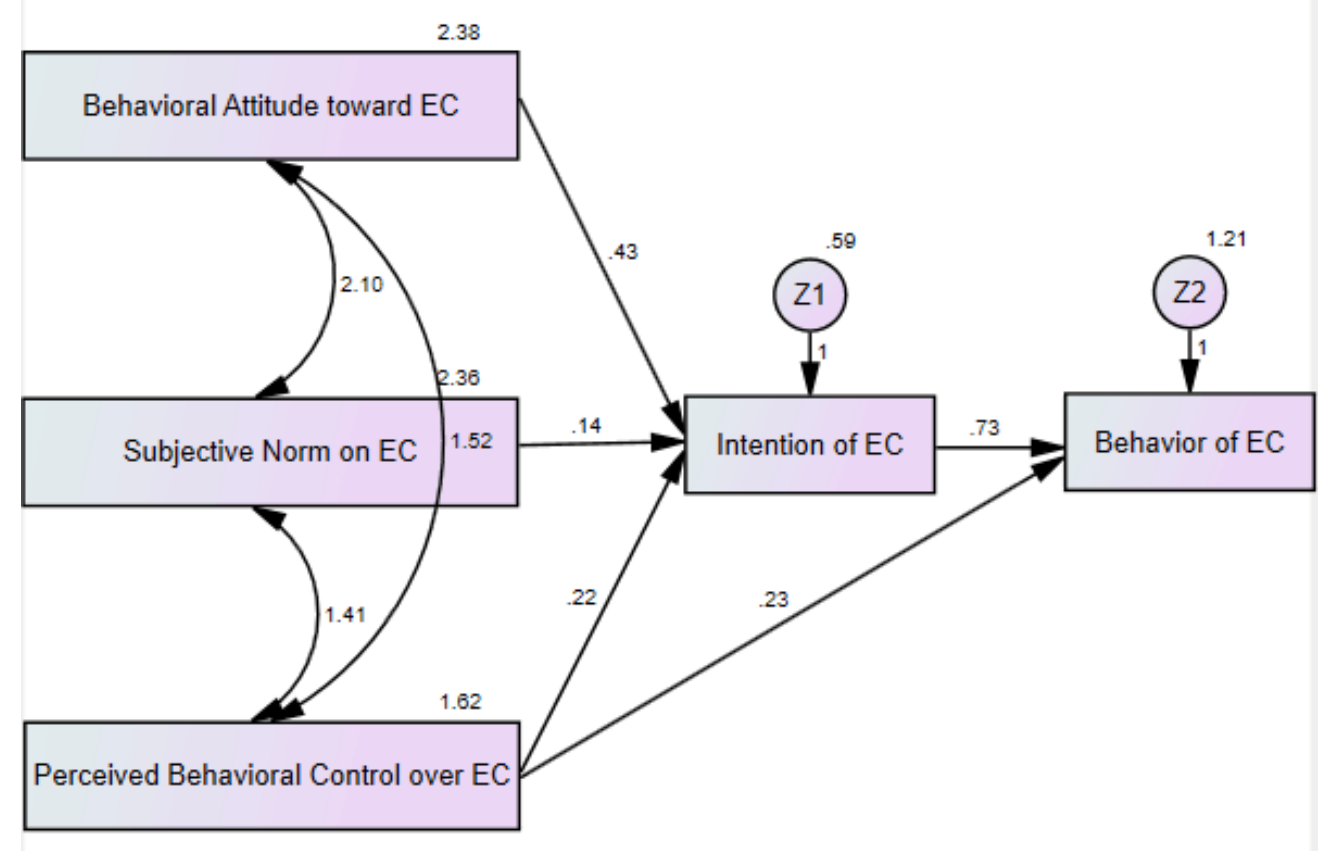

Figure2 Structural Equation Model

Table6 Goodness-of-fit and Parameter Estimate for Default Model

\begin{tabular}{|l|ccccc|}
\hline \multicolumn{1}{|c|}{ Path } & Estimate & S.E. & C.R. & P & result \\
\hline H1: SN on EC <--> BA towards EC & 2.103 & .103 & 20.513 & $* * *$ & Y \\
H2: SN on EC <--> PBC over EC & 1.411 & .078 & 18.059 & $* * *$ & Y \\
H3: BA towards EC <--> PBC over EC & 1.525 & .080 & 18.946 & $* * *$ & Y \\
H4: Intention of EC <---BA toward EC & .431 & .039 & 11.115 & $* * *$ & Y \\
H5: Intention of EC <---SN on EC & .141 & .035 & 4.001 & $* * *$ & Y \\
H6: Intention of EC <---PBC over EC & .221 & .031 & 7.087 & $* * *$ & Y \\
H7: Behavior of EC <---Intention of EC & .728 & .038 & 19.264 & $* * *$ & Y \\
H8: Behavior of EC <---PBC over EC & .227 & .040 & 5.718 & $* * *$ & Y \\
\hline
\end{tabular}

*** Denotes significant at the 0.001 level.

** Denotes significant at the 0.01 level.

* Denotes significant at the 0.05 level.

These results show that parameter estimate of paths among three variables -behavioral attitude, subjective norm and perceived behavioral control- are all significant at the 0.001 level. BA, SN and PBC significantly influence each other. The coefficients of path from BA, SN and PBC to EC intention are respectively $0.431,0.141$ and 0.221 , all of which are significant at the 0.001 level. Therefore, H3, H4, and $\mathrm{H} 5$ are verified. Path coefficients from intention, PBC to behavior of EC, significant at the same level of 0.001 are respectively 0.728 and 0.227 , 
which provides verification of $\mathrm{H7}$ and $\mathrm{H} 8$.

\section{Conclusions and Suggestions}

The research confirms by empirical investigation that, under Network Economy, excessive consuming behavior will be influenced by behavioral intention to consuming excessively, which is further affected together by customers' attitude, Subjective Norm and Perceived Behavioral Control related to over consumption. Meanwhile, Perceived Behavioral Control over excessive consumption will directly influence excessive consuming behavior. It is shown that TPB can adequately interpret the phenomenon of excessive consumption online.

The results include details as follows:

Firstly, behavioral attitude towards excessive consumption has a strong influence on the final behavior as is showed in the research. $12.6 \%$ of the participants declare in the research that they "plan to consume excessively recently" and even $13.8 \%$ of the respondents select to "consume excessively if it is possible", all of which discloses the urgency for related department, in order to encourage rational consumption, to properly conduct an establishment of scientific idea and attitude towards excessive consumption among consumers.

Secondly, compared with behavioral attitude, Subjective Norm on excessive consumption shows little impact on final behavior. It reveals, on the other hand, insufficient public attention to over consumption, which leads to a lack of positive social guide and the impotence for subjective norm to constrain and influence.

Thirdly, Perceived behavioral control influences directly not only behavioral intention but also behavior of excessive consumption. With lower goods price and advanced logistics, $90.2 \%$ of the online consumers agree to the claim that "According to excessively consumption, I have enough knowledge and ability to do so", 82.2\% reckon that consuming excessively will completely under their control. This indicates the great chances that the jeopardy of online over-consumption is underestimated and, thus, negatively aggravate this phenomenon.

With all the results above, we can conclude that it is of great urgency for the public to notice and pay attention to online excessive consumption, have it conducted with the aim to better promote the development of green and sustainable consumerism by conveying a scientific money ethics.

\section{References}

Kahneman and Tversky A. (1979) Prospect theory: An analysis of decision under risk, Econometrical, vol. 47, no. 2, pp. 263-291.

Herbert \& A. Simon. (1955) A Behavioral Model of Rational Choice. Quarterly Journal of Economics, vol. 69, no. 1, pp. 99-118.

Huang, D. H. (2000) Brief Discussion on Rational and Irrational Behavior. Journal of Hebei University of Economics and Trade, vol. 21, no. 3, pp.81-82.

Huang, S. K. (2005) Mechanism of Irrational Consumption. Commercial Research, no. 10, pp. 14-17. 
Lin, B. P. (1991) Dictionary of Consumer Economics, Beijing: Economic Science Press.

Wang, F. N. (2002) A Discussion of Excessive Consumption from the Perspective of Ecology. Studies in Dialectics of Nature, no. 4, pp, 66-67.

Li, Q. Y. (2005) Urgency to pay full attention to Excessive Consumption. Front line, no. 8, pp.21-22.

Huang, H. S. (2005) Advertising Psychology. Beijing: Higher Education Press.

Liang, J. \& Wang, Y. (2007) Reflection on Excessive Consumption Problem. Science Technology and Industry, vol. 7, no. 5, pp.36-38.

Zhu, L. (2006) Discussion on Excessive Consumption.Journal of Tianshui Normal University, vol. 27, no. 4, pp.48-51.

Dutta R, Jarvenpaa S. \& Tomak K. (2003) Impact of feedback and usability of Online payment processes on consumer decision making. Conference Proceedings, $24^{\text {th }}$ International Information System Conference, S.T. March, A Massey, J I DeGross (eds), Seattle, pp. 15-24.

Sandy Dawson \& Minjeong Kim. (2010) Cues on Apparel Web Sites that Trigger Impulse Purchases. Journal of Fashion Marketing and Management, vol 14, no. 2, pp.230-246.

Kathy Ning Shen \& Mohamed Khalifa. (2012) System Design Effects on Online Impulse Buying.Internet Research, vol. 22, no. 4, pp.396-425.

Chen, M. H. (2002) Influences on Impulsive Purchasing of Communication Strategy, Consumer Impulse Characteristics and Product Characteristics. Taiwan: Taiwan University Business Research Institute.

Wang, Q. S. (2008) Research on Online Impulsive Purchase Based on Characteristics of Website and Individual. Zhejiang University.

Zhu, X. D. \& Sun, S. L. (2011) Research on Irrational Consumption on the Internet and Its Influencing Factor. Journal of the Postgraduate of Zhongnan University of Economics and Law, no.1, pp. 16-21

Li, W. (2006) Reflection on Excessive Consumption. Industrial Economic Review, no. 5, pp.53-55.

Qu, H. H. (2001).Brief Discussion about Excessive Consumption.Modern Business, no. 2, pp.10-11.

Ajzen, (1985) From intentions to actions: A theory of planned behavior, In: Kuh1J, BeckmanJ, (Eds.), Action control: From cognition to behavior, Heidelberg,Germa ny:Springer pp. 11-39.

Sheeran, P., Trafimow, D. \& Armitage, C.J. (2003) Predicting behavior from perceived behavioral control: Test of accurance of the theory of planned behavior.British journal of social psychology, no. 42, pp.393-410. 
Hansen T, Jensen J M \& Solgaard H S. (2004) Predicting online grocery buying intention: a comparison of the theory of reasoned action and the theory of planned behavior. International Journal of Information Management, vol. 24, no. 6, pp. 539-550.

Gopi, M. \& Ramayah, T. (2007) Applicability of theory of planned behavior in predicting intention to trade online: Some evidence from a developing country.

International Journal of Emerging Markets, no. 2, pp. 348-360.

George J F. (2004) The Theory of Planned Behavior and Internet Purcha-

Sing. Internet Research, vol. 14, no. 3, pp. 198-212.

Taylor S and Todd P A. (1995) Understanding Information Technology Usage: A Test of Competing Models. Information Systems Research, vol. 6, no. 2, pp. 144-176.

Rong, T. S. (2009) AMOS and Research Method. Chongqing: University Press. 